\title{
THE PRODUCTION OF COHERENT NARRATIVE TEXTS BY OLDER LANGUAGE IMPAIRED CHILDREN.
}

\author{
SHARON TUCH, B.A. (SP. \& H. THERAPY) (WITWATERSRAND) \\ Speech Therapy Department, Transvaal Memorial Hospital for Children, \\ Johannesburg.
}

\section{SUMMARY ,}

A group of 4 language-impaired children, 9 years old, and a group of 4 control children with no language problems were compared on an aspect of 'communicative competence' - their ability to produce coherent narrative texts (sequences of sentences) which were semantically coherent and appropriate to the situational context. A test was devised by the writer, comprising stories presented to the children through a number of sensory modalities. The narrative texts elicited from the 2 groups were compared on a number of measures of ssmantic cohesion and measures of general semantic content (or appropriateness to the situational context). The performance of the languageimpaired children appeared to be inferior to the control group on all the measures of semantic cohesion and general semantic content, supporting the hypothesis that the language-impaired group would perform inferiorly to the control group on an aspect of 'communicative competence'. The implications of the study's findings for the diagnosis and treatment of expressive language problems in the older child were discussed.

\section{OPSOMMING}

'n Groep van 49 -jarige kinders met taalprobleme is vergelyk met 'n kontrole-groep van 4 kinders ten opsigte van 'n aspek van 'kommunikatiewe vermoë'. Ten einde hierdie aspek te ondersoek is hulle vermoè om saamgestelde verhalende paragrawe te produseer, ontleed. Hierdie paragrawe moes ook toepaslik met betrekking tot die situasie wees. Die ondersoeker het vervolgens 'n toets saamgestel, bestaande uit stories wat deur verskeie sensoriese modaliteite aan die kinders meegedeel is. Die verkreë response van beide groepe is vergelyk ten opsigte van ' $n$ aantal maatstawwe van semantiese samehang en maatstawwe van algemene semantiese inhoud (of toepaslikheid tot situasieleidrade). Resultate verkry uit evaluasie van semantiese samehang en semantiese inhoud het getoon dat die groep van kinders met taalprobleme swakker presteer het as die kontrole-groep. Hierdeur word die hipotese, dat kinders met taalprobleme ondergeskik is aan kinders met normale taalontwikkeling ten opsigte van 'kommunikatiewe vermoë', dus gestaaf. Die waarde van bevindinge verkry uit die studie vir die diagnose en behandeling van ekspressiewe taalprobleme in die ouer kind, word vervolgens bespreek.

Linguistics has had an increasing influence on work in language pathology over recent years. Currently, diagnosis and treatment of expressive (and receptive) language problems of the child during the initial years of language acquisition as well as the older child (beyond the first 5 years of language acquisition) has been conducted largely within the linguistic framework of 'grammatical competence' with its emphasis on the grammaticality of single sentences. However, there appears to have been a growing feeling amongst language clinicians that this approach towards diagnosis and treatment of expressive language disorders might not be adequate for expressive language problems in the older child. Whereas the younger child is largely expected to be only 'grammatically competent', the older child should be able to produce 
not only single grammatical sentences but coherent sequences of sentences if he wishes to communicate effectively with others in his environment. This ability appears to require both greater linguistic and cognitive skill and might be deficient in older children, who, having passed the period of early language acquisition, may by this time have acquired 'grammatical competence' at the single sentence level.

Recent developments in modern linguistic theory appear to offer both a conceptual framework as well as a method of analysis with which to evaluate such an ability and to remediate possible deficits in this ability. Growing dissatisfaction expressed by a number of linguists ${ }^{10,19}$ with modern linguistic theory's notion of 'grammatical competence' has led to the introduction of (1) a new conceptualisation of 'competence' - 'communicative competence' as well as (2) a method of analysis with which to investigate this new conceptualisation of 'competence' - 'discourse analysis'. Each of these will be considered briefly.

Modern linguistic theory, largely based on the generative model of language put forward by Chomsky, ${ }^{4}$ has recognised that the world of modern linguistics comprises 2 parts - 'linguistic competence' and 'linguistic performance'. 'Linguistic performance' has been conceptualised as the native speakerlistener's actual production and understanding of an indefinite number of isolated context-less grammatical sentences, generally never spoken nor heard before. 'Linguistic competence' has been conceptualised as the set of rules which characterizes the native speaker-listener's abstract, underlying knowledge of his language which permits the 'linguistic performance' discussed above. ${ }^{17}$ Modern linguistic theory until recently has aimed to concern itself exclusively with the formulation of the rules of this particular conceptualisation of 'competence' which will hence be termed 'grammatical competence'.13

Criticism has been levelled by certain linguists ${ }^{10,19}$ against linguistic theory's notion of 'grammatical competence' as this characterization of 'competence' makes possible 'performance' which does not approximate performance in actual speaking situations. In order to communicate effectively with others in his environment, it does not suffice for the listener-speaker to produce (and understand) an indefinite number of isolated sentences. In addition, he must be able to produce (and understand) connected discourse defined by Harris ${ }^{8}$ as . . . sentences spoken or written in succession by one or more persons in a single situation, these sentences being appropriate to their situational context. In order to account for this ability to produce sentences appropriate to their verbal and situational context, certain linguists 10,19 have recognised the need to supplement the restricted notion of 'grammatical competence' with an additional conceptualisation of 'competence' - 'communicative competence' - and 'performance' has been reconceptualised as the actual application of 'communicative' and 'grammatical competence' in real-life speaking situations. ${ }^{20}$

As 'communicative competence' involves the ability to produce sentences appropriate to their verbal and situational context, the data used for analysis can no longer be the corpus of isolated context-less sentences used for the investigation of 'grammatical competence'. The data used must necessarily be 
'connected discourse' as defined above by Harris. ${ }^{8}$ The term designated for this type of analysis is 'discourse analysis'. (The terms 'discourse' and 'text' will be used interchangeably). Discourse analysis concerns itself with the ... isolation of linguistic features which differentiate a coherent (connected) sequence of sentences - a text - from an agglomerate of sentences. ${ }^{B}$ The majority of work on text cohesion (relation between sentences) ${ }^{7}$ has dealt with the syntactic aspects of intersentence dependence or relation and has considered different syntactic types of intersentence relation. Amongst these are the two types of intersentence relation investigated in the present study: (1) the use of 'anaphora', when one element in a sentence refers back to an earlier sentence and (2) the use of conjunctions.

However, there has been growing realization that the consideration of semantic, in addition to syntactic, aspects of intersentence relation is essential if the problem of text cohesion is to be successfully resolved. ${ }^{8}$ Gleason ${ }^{8}$ in his discussion of semantic cohesion in narrative texts stated that the most important aspect of semantic ('deep' in Gleason's terminology) cohesion is the chain of events which 'forms the backbone of the narrative'. Gleason's scheme, the 'event line' has been adapted for the semantic analysis in the present study.

Research into the child's development of this aspect of 'communicative competence' (as well as other aspects of 'communicative competence') has been limited. Since 1960, investigations $9,13,14,15$ have focused on the development of the structure of the single sentence and did not consider the ability to produce coherent sequences of sentences. Piaget, ${ }^{16}$ despite the fact that he has not worked within a linguistic framework, did investigate in a portion of his work the development of communication skills - the child's ability to produce coherent sequences of sentences appropriate to the situation. Piaget's work is considered to have relevance for the present study for the following reasons:-

(1) It has provided a certain amount of information on the development, with age, of the ability to produce sequences of sentences - the progression from 'egocentric' to 'socialised' language.

Piaget isolated the features of 'egocentric language', a number of which were considered in the evaluation of the ability in this study. ${ }^{6}$

His work provided a perspective on factors which might account for deficits in this ability. 5

While a limited amount of research has been done (notably by Piaget ${ }^{16}$ and Flavell ${ }^{5}$ ) on the development of communication skills, no research to the author's knowledge has been conducted within a linguistic framework into the ability of normal or language-impaired children to produce coherent sequences of sentences appropriate to the situational context - an aspect of 'communicative competence.'

The present study aimed to investigate this aspect of "communicative competence' in both normal and language-impaired older children. The study was undertaken with a view to:

(1) providing a more comprehensive framework for the diagnosis and treat- 
ment of expressive language problems in the older child - a framework which would incorporate 'communicative competence' in addition to 'grammatical competence'.

(2) suggesting a method of analysis with which to evaluate an aspect of "communicative competence' - 'discourse analysis'.

(3) offering a test which might be used to appraise an aspect of 'communicative competence'.

\section{METHODOLOGY}

\section{AIM}

To compare two groups of 9.year-old children, a language-impaired and a normal group, on an aspect of 'communicative competence' - their ability to produce narrative texts which are semantically coherent and appropriate to the situational context.

More specifically the study aims to compare the two groups on:

(1) their ability to provide the chain of events which according to Gleason 8 'forms the backbone' of the stories presented to them. This involves the appraisal of general semantic content (or appropriateness to the situational context) as well as an appraisal of the most important aspect of semantic cohesion. ${ }^{8}$

(2) their use of two types of intersentence relation, which contribute to the semantic cohesion within a text.

(a) their use of conjunctions which are semantically appropriate as well as their use of conjunctions acquired later in the developmental sequence of language acquisition.

(b) their anaphoric use of pronouns with non-ambiguous referents.

\section{SUBJECTS}

Two groups of subjects (Ss) were used, an Experimental group (E grp.) and Control group (C grp.). Each group comprised $4 \mathrm{Ss}, 3$ girls and 1 boy. All Ss came from monolingual English-speaking home environments.

The E grp. comprised Ss diagnosed by a speech-therapist or remedial teacher to have language problems of a predominantly expressive nature. The Ss were attending either private remedial schools or 'pilot' (remedial) classes in Government schools. The criteria for the selection of the E grp. were

(1) Age - E Ss were required to be between $8^{1 / 2}$ to $91 / 4$ years of age. This particular age range was selected as it was believed, on the basis of work done by Piaget, ${ }^{16}$ and a pilot study carried out by the present author, that children should by this age have acquired the particular aspect of 'communicative competence' investigated in the study.

(2) Intellectual Functioning - all children were required to be of average intellectual functioning, judged on the basis of a full scale I.Q. assessment range of 100-110. I.Q. tests had been carried out recently at the schools. This was considered necessary as $\mathrm{C}$. Chomsky ${ }^{3}$ found that the stage of language acquisition reached by children was related to I.Q. 
(3) Socio-economic Level - All E Ss appeared to be from middle-class backgrounds in terms of the areas where they lived and the occupational status of their fathers (all white-collar workers - professional or in important business positions e.g. managers or directors). It was considered necessary to use Ss from middle-class backgrounds in view of the work done by Bernstein ${ }^{1}$. On the effect of lower-class backgrounds on children's language.

It was originally required that E Ss had no visual perceptual difficulties. This was considered to be of importance as a portion of the test used by the writer involved picture interpretation. However, it was not possible to obtain Ss with exclusively language problems. All E Ss were reported in their remedial assessments to have visual perceptual difficulties largely with regard to their perception of form rather than pictures per se. It was recognized that, if their performance on the portion of the test involving picture interpretation was inadequate, the influence of visual perceptual difficulties rather than linguistic factors could not be ruled out.

Three of the four Ss had received speech therapy, two of whom were still re. ceiving speech therapy. The fourth $\mathrm{E} S \mathrm{~S}$ had only recently been diagnosed to have a language problem. The varied amount of speech therapy received by the E Ss did not appear to be a critical factor as all the E Ss were still considered to have language problems.

The $\mathrm{C}$ grp. comprised $\mathrm{S}$ s reported by their teachers to have no language prob. lems or problems of any nature. These Ss were all attending the same Government school. The following variables were considered in the matching of the $\mathrm{C}$ and $\mathrm{E}$ grps:-
(1) Age;
(2) Sex;
(3) Intellectual functioning;
(4) Socio-economic background.

\section{TEST USED}

In view of the unsuitability of available tests to assess children's ability to produce narrative texts, the present author devised her own test, following a pilot study which cannot be elaborated on in the present article. The test comprised:-

(1) 4 different picture sequences (of 6 pictures each) each relating a story.

(2) 2 verbal stories.

The stories were presented in three different ways, distinguished in terms of the sensory modality of input or combination thereof. Each presentation of a story was followed by the elicitation of a narrative text from the child about the story. The three types of story presentation were:

(1) input through the visual modality - two picture sequences were presented. to the child.

(2) input through the auditory modality another two stories were recounted verbally (auditorily) to the "child.

(3) input through a combination of the visual and auditory modalities - a further two picture sequences were presented to the child, accompanied 
by a verbal description of the sequence of events depicted in the picture sequence.

The reasons for varying the nature of the input in the presentation of the stories were the following:

(1) It was postulated that the demands imposed by the different modalities were not entirely the same. An investigation of the effect of modality on performance was conside red of value.

(2) Information about events contained in a narrative text is originally received through a number of possible modalities.

It was thus believed that stories presented through different modalities or combinations thereof would elicit discourse which was more representative of real-life spoken discourse than the presentation of stories through a single modality.

All stories were intended to be of a comparable nature in view of the writer's intention to determine the effect of different modalities on performance without the interference of the variable of story content. The following factors were considered:-

(1) The nature of the content (stories depicted every-day events).

(2) The number of main events per story.

(3) The nature of the relationship between main events (causal or temporal).

(4) The number of pictures per picture sequence.

(5) The number of sentences and the nature of the syntax of the sentences in the auditory stories.

Pictures were designed to be as clear and non-ambiguous as possible. Factors considered by the writer to ensure the clarity of the pictures were (1) Picture size (2) Background - the reduction of distracting background detail and (3) Realism. ${ }^{11}$ Thus any possible pictorial misinterpretation by the children could not be attributed to the lack of clarity of the pictures.

\section{PROCEDURE}

(1) Testing of each of the eight Ss was conducted individually during a single 30-minute session under quiet conditions with only the tester (the writer) and the subject present in the room.

(2) Instructions were provided and a trial picture story was presented to the child (not analysed) in order to ascertain that the child "understood the task required of him and to familiarise him with the test situation.

(3) The tester then presented the 6 stories, each followed by the elicitation of a narrative text about the particular story presented. The stories used in a particular modality were the same for each child.

(4) The order of modality presentation was varied systematically for each child to eliminate a practice effect.

(5) The child was given as much time as he required before telling the story in order to elicit narrative texts to the best of the child's ability. 
(6) All four auditory stories were pre-recorded on a tape recorder to ensure uniformity in the presentation of stories.

(7) The narrative texts of the children were recorded on a second taperecorder.

(8) Though six narrative texts (two per modality) were elicited from each child, three narrative texts (one per modality) were analysed for each child in view of time limitations. The three particular texts analysed were selected randomly but were the same for all Ss.

(9) The three narrative texts. were analysed and scored in terms of a number of measures and the scores for the two groups on these measures were compared (See MEASURES below). The influence of modality was investigated only for measures of the ability to provide the chain of events: it was believed that the performance on this measure might be most affected by different sensory modalities.

(10) A descriptive rather than inferential statistical analysis of the results was carried out: the results were not considered to lend themselves to a reliable inferential statistical analysis in view of the 'open ended' responses of the children.

\section{MEASURES USED AND THEIR SCORING}

The following measures were used:

I. Measures of the ability to provide the chain of events which 'forms the backbone of the narrative' stories presented to the children. These measures were suggested by Gleason's concept of the 'event line'. Measures of this ability were divided into two categories:-

(a) Measures of the ability to provide the general semantic content of the story presented, i.e. measures of the ability to respond appropriately to the situational context - the story-stimuli presented.

(b) Measures of the ability to provide a semantically (or logically) coherent narrative text. Only those deviations in content which affected the semantic cohesion of the narrative text were recorded here.

It was necessary to distinguish these two categories as deviations in content affecting not only semantic accuracy but also, the logic of the story resulted in a greater disturbance of meaning and appeared to suggest possible difficulties at the higher cognitive level of logical thinking or reasoning.

The three stories presented to the children were each broken down into a number of main events, the omission of which would alter either the content or both the content and semantic cohesion of the text. (Children were not required to provide the precise wording of the main events outlined but to convey rather the 'idea' of these events.) The three narrative texts of each child were analysed in terms of the following:

(a) Measures of content consisted of the total number of (1) main events omitted per story, and (2) number of inaccuracies concerning the main events per story. It was considered necessary to include this latter measure as children, on occasions provided a main event with an inaccuracy concerning a particular aspect of the event, which altered to 
some extent the content of the story. (3) The number of additional events provided per story were noted. These events described very concrete aspects of the situation portrayed in the story and were of no relevance to the story, they tended to obscure the main events of the story.

(b) Measures of semantic (or logical) cohesion consisted of (1) the number of main events omitted, affecting story logic per story, (2) the number of inaccuracies affecting logic per story, and (3) the frequency of incorrect verbal sequencing of main events per story. These instances of incorrect sequencing disturbed the semantic cohesion of the text.

\section{Scoring of the Above Measures:}

For Each Child: For each of the measures (a) (1), (a) (2), (b) (1) and (b) (2) a percentage was established for each story and a mean percentage for all three stories was computed. For measures (a) (3) and (b) (3) a frequency score was established (e.g. no. of additional events) for each story and then a mean frequency score was tallied.

For each group: For each of measure (a) (1), (a) (2), (b) (1) and (b) (2) a group mean percentage was calculated on each story modality and then a grand group mean percentage for all three modalities together was established. For each of measures (a) (3) and (b) (3) a group mean frequency was tallied for each story modality and then a grand group mean frequency for all three mo. dalities together was established.

Grand group means for all six measures were compared for all the modalities together. Group means for all six measures were compared on each modality.

II. Measures of two types of intersentence relation contributing to the semantic cohesion of the text: (a) conjunctions, and (b) personal pronouns with non-ambiguous referents were used. Both types of intersentence relation contribute to the syntactic in addition to the semantic cohesion within the text. However in the present study only the semantic aspects of intersentence relation were considered.

(A) The use of Conjunctions to link sentences within the text: Conjunctions were divided into two main categories:

- Conjunctions which manifest themselves early in the developmental sequence of language acquisition 'and', 'then' and 'so' used with the seman. tic intent of 'then' rather than 'therefore'.

- Conjunctions which manifest themselves later in the developmental sequence - causal conjunctions ('because' and 'so' used to denote 'therefore'), time conjunctions ('when' and 'until') and other later-developing conjunctions ('but', 'if', 'in case', 'in order to'). ${ }^{12}$ Other later developing conjunctions could not be considered in the study as the nature of the stories was not conducive to their use.

The following two measures were used in the analysis of children's use of conjunctions:

(1) Number of later developing conjunctions used semantically appropriately. 
This measure-suggested by Flavell ${ }^{5}$ was considered of importance as the laterdeveloping conjunctions express more complex relations (than early-developing conjunctions) between the sentences which they link. Their use within a text would thus enhance the semantic cohesion of the text. It was postulated on the basis of the work of Flavell ${ }^{5}$ and Piaget ${ }^{16}$ that the E grp. would use a smaller percentage of these later developing conjunctions semantically appro. priately.

(2) Number of conjunctions used semantically inappropriately.

This measure was considered necessary as a failure to observe the semantic restrictions governing the use of particular conjunctions would lead to a disruption of the semantic cohesion (or continuity) within the text. It was postulated on the basis of Lee's work ${ }^{12}$ that the E grp. would use a higher proportion of conjunctions in a semantically inappropriate manner than the $\mathrm{C}$ grp.

\section{Scoring of the two measures of conjunction use.}

A percentage for each of the two measures was established for each child on the basis of his three narrative texts. Group mean percentages on each measure were obtained and compared.

(B) The use of pronouns with non-ambiguous referent.

The second type of intersentence relation considered was the anaphoric use of personal pronouns i.e. personal pronouns said to substitute for an earlier occurring noun phrase (NP) in a preceding sentence of the text. The writer chose to investigate an aspect of anaphoric pronoun use which was of importance for semantic cohesion - the anaphoric use of personal pronouns with non-ambiguous referents (a measure suggested by Piaget ${ }^{16}$ ). This refers to the use of a pronoun only when the earlier occurring NP, to which it is intended to refer, is not to be confused with other earlier occurring NPs.

Ambiguous anaphoric use of personal pronouns is more likely to occur when there are two or more human participants in the text of the same sex; or when there are two or more non-human nouns in the text, both singular and plural. The following was investigated: (1) ambiguous use of human personal pronouns ('he', 'him', 'his' or 'she', 'her') in two of the three stories analysed per child; (2) Ambiguous use of non-human personal pronouns ('it' or 'them') in two of the three stories analysed.

It was postulated on the basis of work done by Piaget ${ }^{16}$ and Flávell ${ }^{5}$ that the E grp. would use a higher proportion of personal pronouns ambiguously than the $\mathrm{C}$ grp.

Scoring of ambiguous pronominal use.

Each child's stories were scored in terms of

(1) Number of ambiguous human personal pronouns in two Stories,

(2) Number of ambiguous non-human personal pronouns in two Stories, and 
(3) Number of ambiguous personal pronouns, which was computed as a percentage on the basis of scores (1) and (2). Mean group percentages for (3) were then obtained and compared.

\section{RESULTS AND DISCUSSION.}

Before presenting the results it should be pointed out that conclusions about the significance of differences between the two groups could not be drawn as an inferential statistical analysis was not carried out. It must also be mentioned that, though included in certain tables, consideration of the performance of individual Ss was not possible in this present article. Results for each measure will be presented and discussed.

I. MEASURES OF THE ABILITY TO PROVIDE THE CHAIN OF EVENTS OF THE STORY.

A comparison of the two groups' performance on measures of semantic content and semantic cohesion - all modalities being considered together.

While the disparity between the two groups was small on certain measures, scores for the two groups appeared to indicate that (1) the E grp. performed inferiorly to the $\mathrm{C}$ grp. on all measures of semantic content resulting in their texts being less appropriate to the situational context (or stories presented.) (2) the E grp. performed inferiorly to the $\mathrm{C}$ grp. on all measures of semantic cohesion, the presence of these deviations in semantic cohesion casting greater doubt on the higher cognitive processes of reasoning or logical thought of these children. The two groups performance will be compared firstly in terms of (a) measures of semantic content and then in terms of (b) measures of semantic cohesion (see Table 1).

(a) Measures of content:

(1) The grand mean percentage of events omitted by the E grp. of the total number of events per story was $13,6 \%$ for the E grp as compared with 2,5\% for the $\mathrm{C}$ grp. The $\mathrm{E}$ grp thus showed a tendency to omit more events of a story than the $\mathrm{C}$ grp.

(2) The grand mean percentage of inaccuracies concerning the main events of the total number of events per story was $9,5 \%$ for the $E$ grp. and 2,3\% for the $\mathrm{C}$ grp. These results appear to indicate a greater tendency in the $\mathrm{E}$ grp to provide events with inaccuracy.

(3) The mean frequency of additional events per story was 0.5 for the $\mathrm{E}$ grp. and 0 for the $\mathrm{C}$ grp. The disparity between the two groups was small but considered noteworthy in view of the presence of these events in the E grp's texts as compared with their total absence in the C grp's texts. The presence of these events in the texts of the E grp. seems to indicate that the E grp. tended to be more 'concrete-bound' than the $\mathrm{C}$ grp and experienced difficulty on occasions in extracting the main (salient) events of the story from the concrete background occurrences within the story (a more abstract cognitive function). 


\begin{tabular}{|c|c|c|c|c|c|c|c|c|}
\hline \multirow[t]{2}{*}{ MEASURES } & \multicolumn{2}{|c|}{ VISUAL } & \multicolumn{2}{|c|}{ AUDITORY } & \multicolumn{2}{|c|}{$\begin{array}{l}\text { VISUAL \& } \\
\text { AUDITORY }\end{array}$} & \multicolumn{2}{|c|}{$\begin{array}{l}\text { ALL MODALITIES } \\
\text { TOGETHER }\end{array}$} \\
\hline & E & $\mathrm{C}$ & $\mathrm{E}$ & $\mathrm{C}$ & E & $\mathrm{C}$ & $\mathbf{E}$ & $\mathrm{C}$ \\
\hline $\begin{array}{l}\text { Percentage of events } \\
\text { omitted of the total no. of } \\
\text { events per story }\end{array}$ & $14 \%$ & - & $16 \%$ & $4 \%$ & $11 \%$ & $3,5 \%$ & $13,6 \%$ & $2,5 \%$ \\
\hline $\begin{array}{l}\text { Percentage of inaccuracies } \\
\text { about events of the total } \\
\text { no. of events per story }\end{array}$ & $25 \%$ & $7 \%$ & - & - & $3,5 \%$ & - & $9,5 \%$ & $2,3 \%$ \\
\hline $\begin{array}{l}\text { Frequency of additional } \\
\text { events per story }\end{array}$ &, 75 & - &, 25 & - & - & - &, 33 & - \\
\hline $\begin{array}{l}\text { Percentage of events } \\
\text { omitted affecting semantic } \\
\text { cohesion of the total no. } \\
\text { of events per story }\end{array}$ & $7 \%$ & - & $16 \%$ & - & $7 \%$ & $3,5 \%$ & $10 \%$ & $1,2 \%$ \\
\hline $\begin{array}{l}\text { Percentage of inaccuracies } \\
\text { affecting semantic } \\
\text { cohesion of the total no. } \\
\text { of events per story }\end{array}$ & $18 \%$ & - & - & - & - & - & $6 \%$ & - \\
\hline $\begin{array}{l}\text { Frequency of incorrect } \\
\text { sequencing per story }\end{array}$ &, 5 & - &, 25 & - & - & - &, 25 & - \\
\hline
\end{tabular}

TABLE 1 E and C group means on semantic measures of content and cohesion by modality and all the modalities together.

(b) Measures of semantic (or logical) cohesion:

(1) The grand mean percentage of omissions of events affecting logical cohesion of the total number of main events per story was $10 \%$ for the E grp. and 1,2\% for the C grp. The E grp thus omitted a greater proportion of events affecting the logical cohesion of their stories.

(2) The grand mean percentages of inaccuracies affecting the semantic cohesion of the story of the total number of events per story was $6 \%$ for the $\mathrm{E}$ grp as compared with $0 \%$ for the $\mathrm{C}$ grp. While the disparity in percentage between the two groups on this measure was small, it did appear that the E grp tended to provide a greater proportion of inaccuracies affecting the logical cohesion of their stories as compared with the $\mathrm{C}$ grp.

(3) The grand mean frequency of incorrect sequence per text was 0,25 for the $\mathrm{E}$ grp and 0 for the $\mathrm{C}$ grp. The disparity in frequency between the two groups was again small; however, it was considered noteworthy that there was a total absence of incorrect verbal sequencing in the $\mathrm{C}$ grp, whereas there were a number of these instances in the E grp's stories. 


\section{The effect of modality.}

An in-depth comparison of the performance of the groups on the different story modalities was not made in view of the limited number of texts (one text) per modality for each $S$. On the basis of the brief comparison made, the reliability of which is recognised to be uncertain, it was apparent that the $\mathrm{E}$ grp performed inferiorly to the $\mathrm{C}$ grp on each modality. This appears to indicate that the inferior semantic performance of the $\mathrm{E}$ grp as a whole was not modality dependent.

It was, however, of interest that the largest differences between the two groups occurred in the visual modality where the E grp performed inferiorly to the $\mathrm{C}$ grp on all the semantic measures used for the analysis. This appeared attributable in part to the visual perceptual difficulties which the children reportedly experienced. In addition, the interpretive (perceptual-cognitive) demands appeared to be greater in this modality as compared with the audi-. tory modality and the combination of the visual and auditory modalities where the salient events had already been extracted for the child in the verbal (auditory) presentation. The finding appears to have important implications for the language therapist working with language-impaired children - the therapist should consider the possibility of visual in addition to language problems with such children.

\section{Factors postulated to account for the inferior performance of the E grp on} the above semantic measures.

(1) Difficulty in the gaining of meaning from the different modalities of input - visual and auditory: In order to gain meaning from these modalities, the following skills are necessary (a) perceptual skills (auditory and visual), (b) verbal comprehension (for auditory modality) and (c) cognitive skills - the ability to extract only the salient (main) events of the story and the logical and temporal relations between these events. The E grp may have experienced difficulty in the gaining of meaning from the modalities of presentation due to deficits at one or a number of these levels which appear to be interrelated aspects of cognition. Piaget ${ }^{16}$ attributed deficits in perceptual and cognitive skills (which appeared to be reflected in some of the children's misinterpretation and distortion of events) to the child's generalised cognitive "egocentrism' - his being a 'prisoner of his own point of view.'

(2) Difficulty in expressing meaning which the child has in fact grasped:

It is possible that in certain instances the E Ss were able to grasp the salient events of the story and the relations between them, but had difficulty in providing the events accurately and in the correct sequence due to expressive language difficulties involving syntax and/or vocabulary. In addition, Piaget ${ }^{16}$ maintains that the child up to $7-8$ years of age tends to omit events and provide them in the incorrect sequence due to his failure to consider the listener's point of view ("egocentric language') which Piaget considered to be a further manifestation of the child's generalised cognitive 'egocentrism', his functioning at a less mature cognitive level. 
It is postulated by the writer that an interaction of both the above groups of factors (linguistic and cognitive) might have accounted for the inferior performance of the E grp on the above semantic measures (of content and cohesion). It is recognised that the relative contribution of these factors may have varied for individual E Ss.

\section{MEASURES OF THE USE OF 2 TYPES OF INTERSENTENCE RELATION}

(A) Use of conjunctions.

(1) The mean percentage of later developing conjunctions used semantically appropriately of the total number of conjunctions used was 20,5\% for the E grp and 33\% for the C grp. (See Table II).

The E grp thus used a lower mean percentage of later developing conjunctions semantically appropriately as compared with the $\mathrm{C}$ grp. As the later developing conjunctions establish more complex and intimate relationships between the sentences of a text, the semantic cohesion of the E grp's texts thus appeared to be somewhat reduced in relation to the cohesion of the $\mathrm{C}$ grp's texts. Two factors, one or both of which (as in the case of semantic measures of content and cohesion) may be operative, are postulated to account for the lower percentage of later developing conjunctions found in the E grp: (i) a cognitive factor - Piaget ${ }^{16}$ maintains that the use of causal and logical conjunctions (the majority of later developing conjunctions being logical and causal) in children's spontaneous language develops as children begin to grasp the actual causal and logical relationships expressed by these conjunctions. The lack of causal and logical conjunctions was considered by Piaget to be a feature of the child's 'egocentric language'. It is possible that the E grp had not mastered to the same extent as the $\mathrm{C}$ grp these logical and causal relationships and were thus cognitively delayed in relation to the $C$ grp. (ii) Linguistic factors - it is possible that the E grp did have a non-linguistic (or cognitive) understanding of these causal and logical relationships but did not have the linguistic means (vocabulary of conjunctions and/or syntactic ability) to express these relationships. It would appear that the process of subordination, involved in the use of most later-developing conjunctions, ${ }^{12}$ imposes greater syntactic demands on the child as subordination involves the linking of units which are constituents at different levels, whereas co-ordination (involved in the use of early conjunctions) involves the linking of units which are constituents at the same level.

It is believed that future investigation of the use of later-developing conjunctions may be carried out even more effectively using stories which provide greater scope for the utilisation of these conjunctions. 


\begin{tabular}{|l|l|}
\hline Ss & *See Across \\
\hline E1 & 44 \\
\hline E2 & 16 \\
\cline { 2 - 2 } E3 & 22 \\
\hline E4 & 0 \\
\hline$\overline{\mathbf{x}} \overline{\text { E } \text { grp }}$ & 20,5 \\
\hline \hline C1 & 40 \\
\hline C2 & 20 \\
\hline C3 & 36 \\
\hline C4 & 35 \\
\hline \hline $\bar{x}$ C grp & 33 \\
\hline
\end{tabular}

* Later-developing conjunctions used semantically appropriately as a percentage of the total no. of conjunctions (early and late-developing) used.

TABLE II Later developing conjunctions used semantically appropriately as a percentage of the total number of conjunctions used by $S$ and Group

(2) The percentage of conjunctions used semantically inappropriately of the total number of conjunctions used was $10 \%$ for the $E$ grp and $1 \%$ for the $\mathrm{C}$ grp (see Table III).

While it is difficult to comment on the magnitude of the differences between the 2 groups, it is apparent that the E grp used a higher proportion of conjunctions in a semantically inappropriate manner as compared with the $\mathrm{C}$ grp. As semantic errors in conjunction use disrupt the semantic cohesion or continuity of the text, the higher proportion of semantically inappropriate conjunctions in the $\mathrm{E}$ grp. was responsible for reduced semantic cohesion within their texts.

Semantic errors in conjunction use in the E grp. occurred for both earlier and later-developing conjunctions and would reflect the E grp's failure on occasions to observe the semantic restrictions governing the use of these conjunctions e.g. the conjunction 'then' can be used to link two sentences only when the action described in the sentence preceding the conjunction is complete (not ongoing) prior to the action contained in the sentence following the conjunction. This finding of greater semantic inappropriateness appeared to be in agreement with Lee ${ }^{12}$ who 


\begin{tabular}{|c|c|}
\hline Ss & $\begin{array}{c}\text { Percentage } \\
\text { Inappropriate }\end{array}$ \\
\hline $\mathrm{E} 1$ & $8 \%$ \\
\hline $\mathrm{E} 2$ & $0 \%$ \\
$\mathrm{E} 3$ & $\frac{22 \%}{10 \%}$ \\
\hline \hline$\overline{\mathrm{x}} \mathrm{grp}$ & $10 \%$ \\
\hline \hline $\mathrm{C} 1$ & $0 \%$ \\
\hline $\mathrm{C} 2$ & $5 \%$ \\
\hline $\mathrm{C} 3$ & $0 \%$ \\
\hline $\mathrm{C} 4$ & $0 \%$ \\
\hline \hline$\overline{\mathrm{x} C} \mathrm{grp}$ & $1,25 \%$ \\
\hline \hline
\end{tabular}

TABLE III Conjunctions used semantically inappropriately as a percentage of the total number of conjunctions used by $\mathrm{S}$ and Group.

reports that . . . some children in clinical language training show difficulty learning the semantic constraints of conjunction selection and will make inappropriate choices.

B A measure of the anaphoric use of personal pronouns with non-ambiguous referents:-

The mean group percentage of pronouns used ambiguously (i.e. with two possible referents) of the total number of personal pronouns used anaphorically in the texts investigated was $13,5 \%$ for the E grp and $1 \%$ for the $\mathrm{C}$ grp.

It is evident that the $E$ grp used a greater percentage of pronouns ambiguously as compared with the $\mathrm{C}$ grp. The greater occurrence of ambiguous pronominal usage in the $E$ grp reduced to some extent the semantic cohesion of their texts as well as their communicative efficacy as compared with' the $C$ grp.

Again two factors, one or both of which may be operative, are postulated to account for this greater tendency in the E grp. to use pronouns with ambiguous referents:-

A cognitive factor - Piaget ${ }^{16}$ maintains that the use of pronouns with nonexplicit referents is a feature of 'egocentric' language. According to Píaget, 'egocentric' language declines as a function of the child's 
cognitive development and is replaced by 'socialised' language. It is thus possible that the E grp, at 9 years of age, were still using pronouns with ambiguous.referents in view of cognitive delay.

A linguistic factor - it is possible that the E grp do consider the listener's point of view (and are thus not cognitively delayed in this regard) but are unable to express this consideration in view of other more important linguistic and cognitive demands imposed by the discourse situation. Flavell ${ }^{5}$ recognised that seemingly 'egocentric' language might not be attributable to a failure to consider the listener's point of view per se but rather to deficits in linguistic skills.

Further investigation of ambiguous pronominal use may be enhanced by consideration of the following points:

(1) Demands on the ability to use pronouns with non-ambiguous referents may be increased by the use of stories involving more than two participants of the same sex or more than two non-human nouns (singular or plural).

(2) The use of auditory stories or visual stimuli no longer present in the testing situation is likely to increase the speaker's need to be explicit in his use of pronouns - the listener is less able to extract the appropriate referent in the absence of pictures.

\section{GENERAL DISCUSSION AND CONCLUSION}

In view of the few deviations on all measures it appeared that the normal 9-year-old group were 'communicatively competent' and that the languageimpaired grp of the same age failed to exhibit the 'communicative competence' required for their age level. The $\mathrm{E}$ grp's inferior performance on the measures used to investigate an aspect of 'communicative competence' appeared to be most comprehensively accounted for by the perspective furnished by Piaget, ${ }^{16}$ and Flavell: ${ }^{5}$ an interaction between both linguistic (semantic and syntactic) and cognitive deficits, the relative contribution of which may have varied for individual $\mathrm{Ss}$.

The findings of the study would suggest that at least certain language impaired children exhibit deficits on an aspect of 'communicative competence' which impair their communication with others in their environment. While the value of diagnosis and treatment of expressive problems in terms of 'grammatical competence' is recognised, it is believed that this approach needs to be supplemented with the concept of 'communicative competence' for the following reason: an approach to expressive language problems in the older child in terms of 'grammatical competence' alone might not be able to detect and hence remediate deficits beyond the single sentence level. Thus it cannot ensure the child's communicative efficacy, effective communication being to some extent dependent on the ability to produce coherent sequences of sentences. Furthermore, such an approach might lead to premature dismissal of children from language the rapy as rehabilitated in terms of 'grammatical com: petence', when, in fact, they still have difficulty in terms of 'communicative competence' which warrants attention. It is further believed that such an approach could also be utilised in the appraisal of aphasic language. 
The present study appears to have a further implication for the approach to expressive language problems in the older (and possibly younger) language-impaired child. The study focused largely on semantic ability (the ability to express meaning) as this ability appears to be crucial for effective communi. cation or 'communicative competence'. All the language-impaired Ss investigated showed deficits in this ability. Despite the report that the E Ss were predominantly expressively impaired, the difficulty in their expression of meaning appeared to be the result, not only of linguistic deficits, but possibly of the interaction between linguistic and perceptual-cognitive deficits. Currently, diagnosis and therapy for expressive language problems focuses largely on linguistic deficits involving syntax and to some extent vocabulary, which only partially accounts for the ability to express meaning. The findings of the study appear to suggest the need for (a) greater emphasis on the ability to express meaning and (b) a more global approach considering both linguistic and cognitive factors even in the diagnosis and treatment of what seem to present as predominantly expressive language problems.

Discourse analysis appeared to be a necessary tool for the investigation of the particular aspect of 'communicative competence' considered in the study. It facilitates the examination of aspects of semantic cohesion which could not be investigated at the single sentence level, except possibly for the use of conjunctions which was nevertheless considered to be more profitably investigated in discourse where there is scope for the conjoining of a greater number of sentences. A consideration of the child's discourse rather than single sentences, lends itself also to the investigation of other features which are of importance for effective communication, though not included in the present study:

(a) Syntactic cohesion established through a number of types of intersentence relation, e.g. ellipsis, tense continuity and the anaphoric use of the determiner 'the' and pro-forms (e.g. pro-verbs, pro-adjective); (b) the ability to produce grammatical sentences in discourse rather than at the isolated sentence level; (c) fluency in a discourse situation.

The test devised was considered to be of value as it enabled an appraisal of the aspect of 'communicative competence' investigated in the study' and proved to be sensitive to deficits in this aspect of 'communicative competence'. It is recognised, however, that a more complex test of a similar nature might have been more appropriate for the age level investigated and revealed even greater differences between the two groups. This can be ascertained only with future research. The test also provided a controlled situation for the investigation of an aspect of 'communicative competence': the content of the children's narrative texts could be evaluated against the content of the stories presented. The test makes it possible to establish the influence of modality of input on this aspect of 'communicative competence' which could have both diagnostic and therapeutic value. The test also enabled an appraisal of what the writer considers to be integrated linguistic functioning' - the ability to gain meaning and then express that meaning, which requires substantial cognitive and linguistic integrity. This integrated linguistic functioning would appear to be the hallmark of 'communicative competence'. Finally, it is believed that the test (or picture and auditory stories 
of a similar nature) could be utilised therapeutically to promote the development of both cognitive and linguistic skill.

In conclusion, further research employing larger samples of Ss and a greater number of texts per $S$ appears advocated to investigate the aspect of "communicative competence' as well as its development with age. As the judgement of 'communicative competence' is ultimately the listener's, the ratings of other speech therapists and untrained listener's of children's 'communicative competence' should be obtained. Also, children should be required to provide information to a listener who is ignorant of this information: this would most likely increase the need on their part to communicate effectively and hence enable a more accurate appraisal of this ability.

\section{REFERENCES}

1. Bernstein, B. (1962): Social Class, Linguistic Codes, and Grammatical Elements. Language \& Speech, 5, 221.240.

2. Brown, R. (1973): A First Language - The Early Stages. George Allen \& Unwin, London.

3. Chomsky, C. (1970): Stages in Language Development and Reading Exposure. Harvard Educational Review, 42 (1), 1-33.

4. Chomsky, N. (1973): Current Issues in Linguistic Theory. Mouton, The Hague.

5. 'Flavell, J. H. (1968): The Development of Role-Taking and Communication Skills in Children. Wiley, New York.

6. Ginsburg, H. \& Opper, S. (1969): Piaget's Theory of Intellectual Development. Prentice Hall, New Jersey.

7. Hasan, R. (1968): Grammatical Cohesion in Spoken and Written English, I. (Programmes in Linguistics and English Teaching, Paper 7) Longman, London.

8. Hendricks, W. O. (1973): Essays on Semiolinguistics and Verbal Art. Mouton, The Hague.

9. Hunt, K. W. (1970): Syntactic Maturity in School Children and Adults. Monographs of the Society for Research in Child Development. 35 (1), serial No. 134.

10. Hymes, D. (1972): On Communicative Competence. In Sociolinguistics. Pride, J. B. \& Holmes, J. (Eds). Penguin.

1.1. Johnson, D. J. \& Myklebust, H. R. (1964): Learning Disabilities. Grune \& Stratton, Inc., New York.

12. Lee, L. (1974): Developmental sentence Analysis. Northwestern University Press, Evanston.

13. Lyons, J. (1973): Introduction. In New Horizons in Linguistics, Lyons, J. (Ed). Penguin, Middlesex.

14. Menyuk, P. (1964): Syntactic Rules used by Children from Preschool through First Grade. Child Development, 35, 533-546. 
15. O'Donnell, R. C., Griffin, W. J. \& Norris, R. C. (1967): Syntax of Kindergarten and Elementary School Children: $A$ Transformational analysis. National Council of Teachers of English, Report No. 8. Champaign, Illinois.

16. Piaget, J. (1926): The Language and Thought of the Child. Routledge \& Kegan Paul Ltd., London.

17. Pit Corder, S. (1973): Introducing Applied Linguistics. Penguin Education, Middlesex.

18. Saling, M. (1976): Personal Communication. Senior Lecturer, Department of Psychology, University of the Witwatersrand, Johannesburg.

19. Wales, R. \& Campbell, R. (1973): The Study of Language Acquisition. In New Horizons in Linguistics, Lyons, J. (Ed.), Penguin, Middlesex.

20. Young, D. N. (1971): A Sociolinguistic Analysis of Some Aspects of Discourse Structure in Newspaper Texts with Proposals for Pedagogic Application. Master's Dissertation, Department of Linguistics, University of Edinburgh. 